OPEN ACCESS

Edited by:

Qiang Xia,

Ningbo University, China

Reviewed by:

Lijun Sun,

Northwest A\&F University, China

Qunyu Gao,

South China University of

Technology, China

*Correspondence:

Yizhe Yan

yanyizhe@zzuli.edu.cn

Miaomiao Shi

chengzi3090@126.com

Specialty section: This article was submitted to

Food Chemistry,

a section of the journal

Frontiers in Nutrition

Received: 24 December 2021

Accepted: 04 January 2022

Published: 07 February 2022

Citation:

Yan Y, Peng B, Niu B, Ji X, He Y and Shi $M$ (2022) Understanding the

Structure, Thermal, Pasting, and Rheological Properties of Potato and Pea Starches Affected by Annealing

Using Plasma-Activated Water.

Front. Nutr. 9:842662.

doi: 10.3389/fnut.2022.842662

\section{Understanding the Structure,} Thermal, Pasting, and Rheological Properties of Potato and Pea Starches Affected by Annealing Using Plasma-Activated Water

\author{
Yizhe Yan ${ }^{1 *}$, Baixiang Peng ${ }^{1}$, Bin $\mathrm{Niu}^{2}$, Xiaolong $\mathrm{Ji}^{1}$, Yuan $\mathrm{He}^{1}$ and Miaomiao Shi ${ }^{1 *}$ \\ ${ }^{1}$ Henan Key Laboratory of Cold Chain Food Quality and Safety Control, College of Food and Bioengineering, Zhengzhou \\ University of Light Industry, Zhengzhou, China, ${ }^{2}$ College of Food Science and Technology, Henan Agricultural University, \\ Zhengzhou, China
}

In this research, annealing (ANN) using plasma-activated water (PAW) was first employed to modify potato and pea starches. Compared with the conventional ANN using distilled water (DW), the granular morphology of two starches was not significantly affected by PAW-ANN. The results of X-ray diffraction (XRD) and Fourier transform infrared (FTIR) spectroscopy showed that PAW-ANN could reduce the long and short-range ordered structure of potato starch while improving the long and short-range ordered structure of pea starch. Differential scanning calorimetry (DSC) analysis indicated that PAW-ANN lowered the gelatinization enthalpy of potato starch and increased the gelatinization enthalpy of pea starch. The analysis of viscosity and dynamic rheological characteristics illustrated that PAW-ANN reduced the peak viscosity and improved the gel strength of starch pastes. PAW-ANN represents a novel modification method for modifying the structure, reducing the viscosity, improving the gel strength of starch, and is very promising for applying in starch-based hydrogels and food additives.

Keywords: plasma-activated water, annealing, structure, physicochemical properties, potato starch, pea starch

\section{INTRODUCTION}

Starch is a significant carbohydrate source for most organisms, which has been widely applied in the food industry, such as papermaking, adhesives and biodegradable plastics, sweeteners, pasta products, and some fermented products (1). Native starch has the limitations of poor hydration performance, low thermal stability, low shear resistance, and high retrogradation rate, while modified starch performs well in terms of compatibility and has a low retrogradation rate, pasty gelation tendency, and gel shrinkage (2). Therefore, modified starch is preferred in the food industry instead of native starch. The modification of starch usually has the following three methods, namely, physical, chemical, and enzyme modification (3). Among them, physical modification is relatively safe and low-cost, and can greatly reduce waste generation (4).

Annealing (ANN) is usually to treat starch for a period of time at a high moisture content (more than $40 \%, w / w$ ) and a low temperature (below $60^{\circ} \mathrm{C}$ ). As a green modification method, ANN has received extensive attention because it only involves water and heat (5). It can usually change the internal structure and physicochemical properties of starch while not damaging the integrity of 
granules, which makes starch easier to be processed and employed in certain specific circumstances. For example, it has been studied that annealed starch was more suitable for application in yogurt, sauce, and low-digestible foods than native starch (6).

Plasma-activated water (PAW) from plasma treatment of distilled water (DW) has the advantages of uniform function, green and environmental protection. PAW will generate an acidic environment and generate active substances, such as hydrogen peroxide, nitric acid, and peroxynitrite, which will cause changes in the $\mathrm{pH}$, redox potential, and conductivity. Recently, PAW has been widely used in food and agriculture yields, such as promoting plant growth, preservation of seafood, and broadspectrum sterilization (7). However, PAW was rarely applied in the starch modification. According to our preliminary studies, PAW alone had no significant influence on the structure and properties of the starch. Therefore, a combination of PAW and other modified technologies could be an effective strategy. Based on this assumption, we have recently explored the combination of PAW and heat-moisture treatment (HMT) on the structure and properties of maize starches (8). PAW-HMT provided an innovative strategy to regulate the structure and digestibility of starch. However, PAW-HMT effect remained limited compared with the conventional HMT (DW-HMT). Therefore, the development of new PAW combined modifications (such as PAW-ANN and PAW-ultrasound) is desired.

In this research, PAW was first employed during ANN to modify potato and pea starches. After being modified with PAWANN, the changes of structure and properties of potato and pea starches were investigated. It is worth mentioning that this green modification method is only involved in plasma, water, and heat. This research will not only propose a new way of starch ANN treatment, but also further expand the application of PAW in starch modification.

\section{MATERIALS AND METHODS}

\section{Materials}

Native potato starch (13.2\% moisture and $21.6 \%$ amylose) was obtained from Qinghai Weston Potato Industry Group Co., Ltd. (Xining, China). Native pea starch (11.3\% moisture and $30.8 \%$ amylose) was obtained from Henan Enmiao Food Co., Ltd. (Zhengzhou, China). A hydrogen peroxide quantitative kit was obtained from Shanghai Sangon Biotech Co., Ltd. (Shanghai, China). Nitrite and nitrate determination kits were obtained from Beyotime Biotechnology Institute (Nantong, China). Other reagents used in this experiment were of analytical grade.

\section{Preparation and Characterization of PAW}

The PAW was obtained by treating $100 \mathrm{ml}$ of distilled water through plasma processing equipment (Easton Geake Automation Equipment Co., Ltd., Shenzhen, China) for $120 \mathrm{s.}$ The power was $750 \mathrm{~W}$ and the working gas was compressed air (0.18 MPa) (8). The $\mathrm{pH} /$ oxidation-reduction potential (ORP) meter and conductivity meter (INESA Scientific Instrument Co., Ltd., Shanghai, China) were, respectively, employed for measuring the $\mathrm{pH}, \mathrm{ORP}$, and conductivity of the PAW.
Additionally, the content of $\mathrm{H}_{2} \mathrm{O}_{2}, \mathrm{NO}^{2-}$, and $\mathrm{NO}^{3-}$ were determined by corresponding assay kits. Notably, PAW was suggested to be further used within $12 \mathrm{~h}$.

\section{ANN of Potato and Pea Starches With PAW or DW}

After drying at $45^{\circ} \mathrm{C}$, the moisture content of potato and pea starches ( $30 \mathrm{~g}$, dry basis) is about $5 \%$. Then, the moisture content of them was adjusted to $60 \%$ using DW or PAW, respectively. The starch samples were put into the reactor with sufficient stirring and then heated in an air oven at $50^{\circ} \mathrm{C}$ for $12 \mathrm{~h}$. Finally, modified starches were obtained through washing, drying, and sieving and marked as DW-Potato, DW-Pea, PAW-Potato, and PAW-Pea, respectively.

\section{Scanning Electron Microscopy}

Morphology of native and modified starch granules was observed using a scanning electron microscope (JSM-6490LV, JEOL, Japan). A small amount of dry-based samples were adhered to the double-sided conductive adhesive and coated with gold in the ion sputtering device (Polaron Sputter Coat System, Model 5001, $\mathrm{UK}$ ) for $120 \mathrm{~s}$ (8). The imaging acceleration voltage of Scanning electron microscopy (SEM) was $20 \mathrm{kV}$. A micrograph of representative particles was chosen and taken at a magnification of $\times 1,000$.

\section{Polarization Light Microscopy}

A suspension of starch samples (1\%,w/w) was obtained by using a solvent of glycerol and water $(1: 1, \mathrm{v} / \mathrm{v})$ and observed under polarized light microscopy (PLM) (BX53M, Olympus Co., Ltd., Japan). The images were observed and taken at $\times 200$ for all starch samples.

\section{X-Ray Diffraction}

Before analysis of X-ray diffraction (XRD), starch samples needed balancing water over a saturated $\mathrm{NaCl}$ solution at room temperature for 1 week (9). Starch samples were analyzed by using an X-ray diffractometer (D8 Advance, Bruker, Karlsruhe, Germany). The detailed test conditions and relative crystallinity (RC) calculation of the starch samples were based on our previous study (8).

\section{Fourier Transform Infrared Spectroscopy}

Fourier transform infrared (FTIR) spectra of starch samples were determined by using an FTIR spectrometer (Vertex 70, Bruker, Karlsruhe, Germany). Before the test, potassium bromide should be dried at $105^{\circ} \mathrm{C}$ for $6 \mathrm{~h}$. A certain amount of samples and potassium bromide (mass ratio: 1:100) were taken in an agate mortar, mixed, and grinded for about $2 \mathrm{~min}$. The ground mixed samples were placed in a tableing mold and compressed with a tableting machine, where the pressure was maintained within the range of $10 \mathrm{MPa}$ for about $1 \mathrm{~min}$ and then taken out for testing. Test conditions: scanning wave number $4,000-400 \mathrm{~cm}^{-1}$, resolution $4 \mathrm{~cm}^{-1}$, scanning time $64 \mathrm{~s}$. The spectra were analyzed by OMNIC8.2 (Version 8.2, Thermo Nicolet Inc., Madison, WI, USA). The absorbance ratio at $1,047 / 1,022 \mathrm{~cm}^{-1}\left(\mathrm{R}_{1047 / 1022}\right)$ can be obtained by deconvolution with a peak width of $38 \mathrm{~cm}^{-1}$ 
TABLE 1 | Physicochemical properties and content of active substances of distilled water (DW) and plasma-activated water (PAW).

\begin{tabular}{|c|c|c|c|c|c|c|}
\hline Water & $\mathrm{pH}$ & Conductivity ( $\mu \mathrm{S} / \mathrm{cm})$ & ORP (mV) & $\mathrm{H}_{2} \mathrm{O}_{2}(\mu \mathrm{mol} / \mathrm{L})$ & $\mathrm{NO}_{2}^{-}(\mu \mathrm{mol} / \mathrm{L})$ & $\mathrm{NO}_{3}^{-}(\mu \mathrm{mol} / \mathrm{L})$ \\
\hline DW & $6.40 \pm 0.05^{a}$ & $4.55 \pm 0.48^{b}$ & $247.00 \pm 2.65^{b}$ & ND & ND & ND \\
\hline PAW & $2.72 \pm 0.01^{b}$ & $764.67 \pm 1.53^{a}$ & $569.67 \pm 1.53^{a}$ & $131.32 \pm 0.91$ & $1,905.22 \pm 0.75$ & $2,075.17 \pm 2.69$ \\
\hline
\end{tabular}

Values are means $\pm S D$; means with the same letters in a column for the same starch do not differ significantly $(p>0.05)$. ND, Not detected.

and enhancement factor of 19 and employed to characterize the short-range ordered structure of starch molecules (8).

\section{Differential Scanning Calorimetry}

Thermal properties of native and modified starches were obtained by using a differential scanning calorimeter (Q20, TA Instruments Inc., Newcastle, DE, USA). The starch (3 mg, dry basis) and distilled water were added with a microliter syringe to a total weight of $12 \mathrm{mg}$ into an aluminum pan. The samples were equilibrated at room temperature for $12 \mathrm{~h}$. Subsequently, the sample pans were gradually scanned from 30 to $120^{\circ} \mathrm{C}$ at a heating rate of $10^{\circ} \mathrm{C} / \mathrm{min}(8)$.

\section{Rapid Viscosity Analyzer}

Pasting characteristics of the starch samples were obtained by using a rapid viscosity analyzer (RVA4500, Perten Instruments, Hägersten, Sweden). Starch samples were suspended in distilled water to make a total weight of $28.0 \mathrm{~g}$ ( $8 \%$ dry starch, w/w) and then analyzed using RVA Standard Procedure 1 profile. The samples were equilibrated at $50^{\circ} \mathrm{C}$ for $1 \mathrm{~min}$, heated to $95^{\circ} \mathrm{C}$ within $222 \mathrm{~s}$, held at $95^{\circ} \mathrm{C}$ for $150 \mathrm{~s}$, cooled back to $50^{\circ} \mathrm{C}$ for $228 \mathrm{~s}$, and then equilibrated at $50^{\circ} \mathrm{C}$ for $2 \mathrm{~min}$. During this process, the paddle speed was kept at $960 \mathrm{rpm}$ for the first $10 \mathrm{~s}$, and then kept at $160 \mathrm{rpm}$. The pasting curves and parameters were obtained by RVA system software.

\section{Dynamic Rheological Properties}

The dynamic rheological properties of starch pastes from the RVA experiment were analyzed by using a rheometer (Discovery HR-1, TA Instruments Inc., Newcastle, DE, USA). Sample pastes were transferred to the rheometer plate $(40 \mathrm{~mm}$ diameter and $1,000 \mu \mathrm{m}$ gap) and equilibrated for $5 \mathrm{~min}$ at $25^{\circ} \mathrm{C}$. The strain was set at $1 \%$ and the frequency was taken at $0.1-20 \mathrm{~Hz} . \mathrm{G}^{\prime}, \mathrm{G}^{\prime \prime}$, and $\tan \delta\left(G^{\prime \prime} / G^{\prime}\right)$ of samples were recorded.

\section{Statistical Analysis}

All experimental data were recorded as the means \pm SDs. ANOVA followed by post-hoc Duncan's multiple range tests $(p<0.05)$ was conducted to determine the significant differences between mean values using the SPSS 26.0 Statistical Software Program (SPSS Inc., Chicago, IL, USA).

\section{RESULTS AND DISCUSSION}

\section{Characterization of PAW}

After 2 min of plasma treatment, the $\mathrm{pH}$ of PAW dropped rapidly from 6.4 to 2.72 , the conductivity value increased from 4.55 to $764.67 \mu \mathrm{S} / \mathrm{cm}$, and the ORP value increased from 247 to $569.67 \mathrm{mV}$ (Table 1). The measured conductivity value can be used to detect whether there were active ions in the water, and the ORP can be used to reflect the macroscopic oxidationreduction performance of all substances in the aqueous solution, depending on the concentration and strength of the oxidant in the solution. During the plasma discharge process, a large number of active chemical substances, such as reactive hydroxyl radicals, singlet oxygen, superoxide, ozone, and active molecule nitrogen species, were generated. These substances interacted with water molecules to further generate $\mathrm{H}^{+}, \mathrm{H}_{2} \mathrm{O}_{2}$, $\mathrm{NO}, \mathrm{NO}^{2-}$, $\mathrm{NO}^{3-}, \mathrm{ONOO}^{-}$, and so on, which led to the changes in the $\mathrm{pH}$ value, conductivity value, and ORP value of the aqueous solution (10). In addition, after plasma treatment, the content of $\mathrm{H}_{2} \mathrm{O}_{2}, \mathrm{NO}^{2-}$, and $\mathrm{NO}^{3-}$ was increased from zero to 131.32 , 1,905.22, and 2,075.17 $\mu \mathrm{mol} / \mathrm{L}$, respectively (Table 1 ), which further verified the above fact.

\section{Granular Morphology \\ Scanning Electron Microscopy}

The SEM micrographs of native and modified starch samples are displayed in Figure 1. Native potato starch granules were oval or spherical, with various sizes and smooth surfaces. The potato starch granules treated with DW-ANN and PAW-ANN had obvious dents and cracks. Native pea starch granules were slender, kidney-shaped, of different sizes, and had many folds (11). After DW-ANN and PAW-ANN, the shape of most pea starch granules did not change significantly, but the surface folds of the granules were deepened, and a few granules appeared with dents and cracks. However, PAW-ANN did not give significantly different results from DW-ANN for two starches.

\section{Polarized Light Microscopy}

The PLM micrographs of native and modified starch samples are displayed in Figure 2. Native starch granules showed a characteristic birefringence pattern (Maltese cross). The strength of birefringence was related to the overall size, relative crystallinity, and crystallite orientation of the crystal grains (12). The polarized cross of native potato starch was complete and obvious. In contrast, the polarized cross of modified potato starch became fuzzy and the shape of the particles became irregular with cracks, which were similar to the observation by SEM. The difference in the polarized cross between native and modified pea starches was not obviously observed. Notably, there was no significant difference between PAW-ANN and DW-ANN for the two starches.

\section{Crystalline Structure}

$\mathrm{X}$-ray diffractograms of starch samples are displayed in Figure 3. Potato starch showed the characteristic diffraction peaks at $2 \theta=$ 

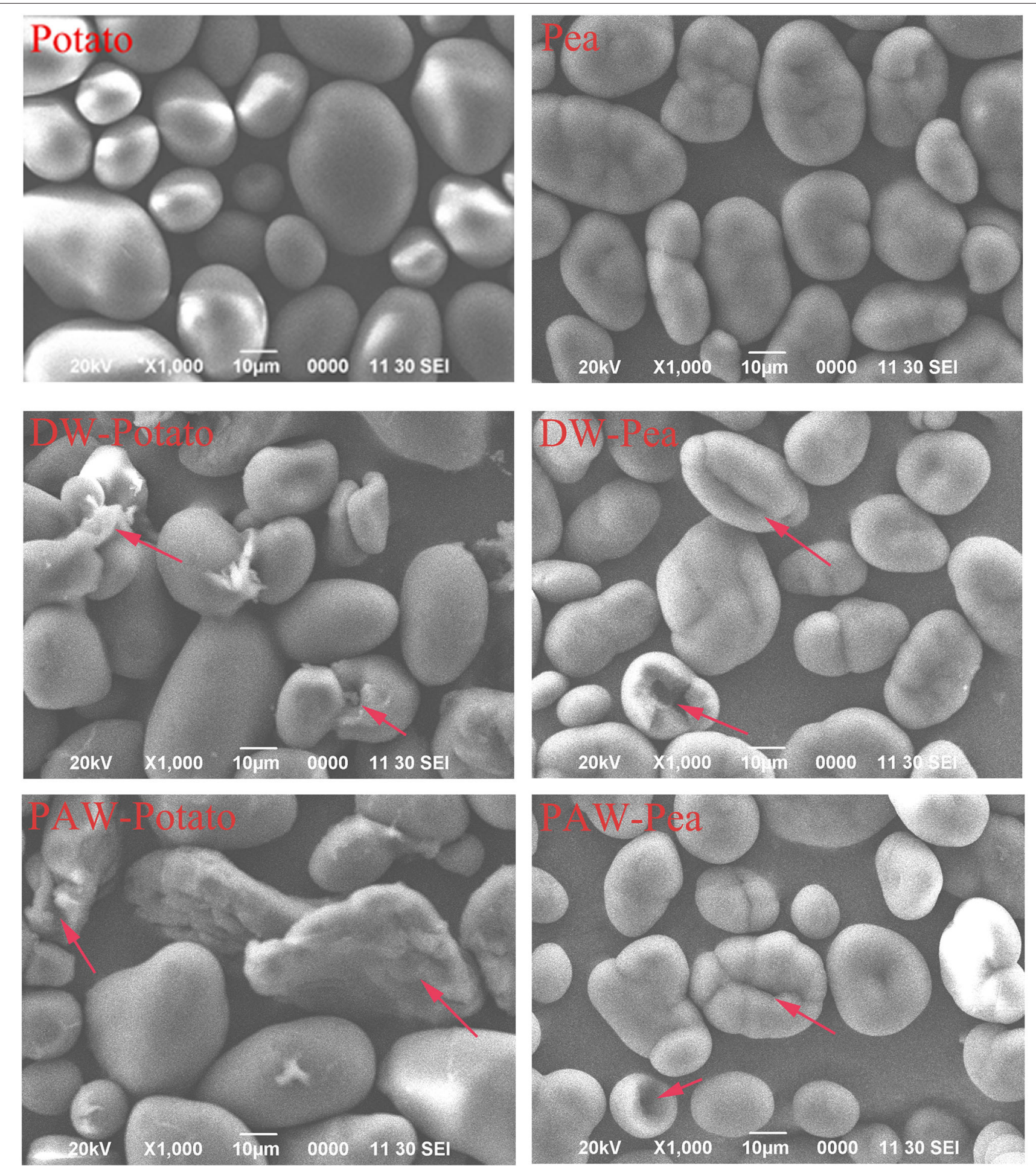

FIGURE 1 | Scanning electron microscopy (SEM) images of native and modified starches.

5.6, 17.1, 22.2, and 24.1 degrees, which was classified to the Btype structure (13). According to Table 2 , the relative crystallinity (RC) of ANN-modified potato starch (DW-Potato and PAWPotato) was lower compared with native potato starch. This might be because the double helix molecules of the B-type crystal structure were more sparsely arranged in space, forming a spiral cavity center (14), so ANN was more likely to destroy its crystal structure. This can be confirmed from the observations of the 

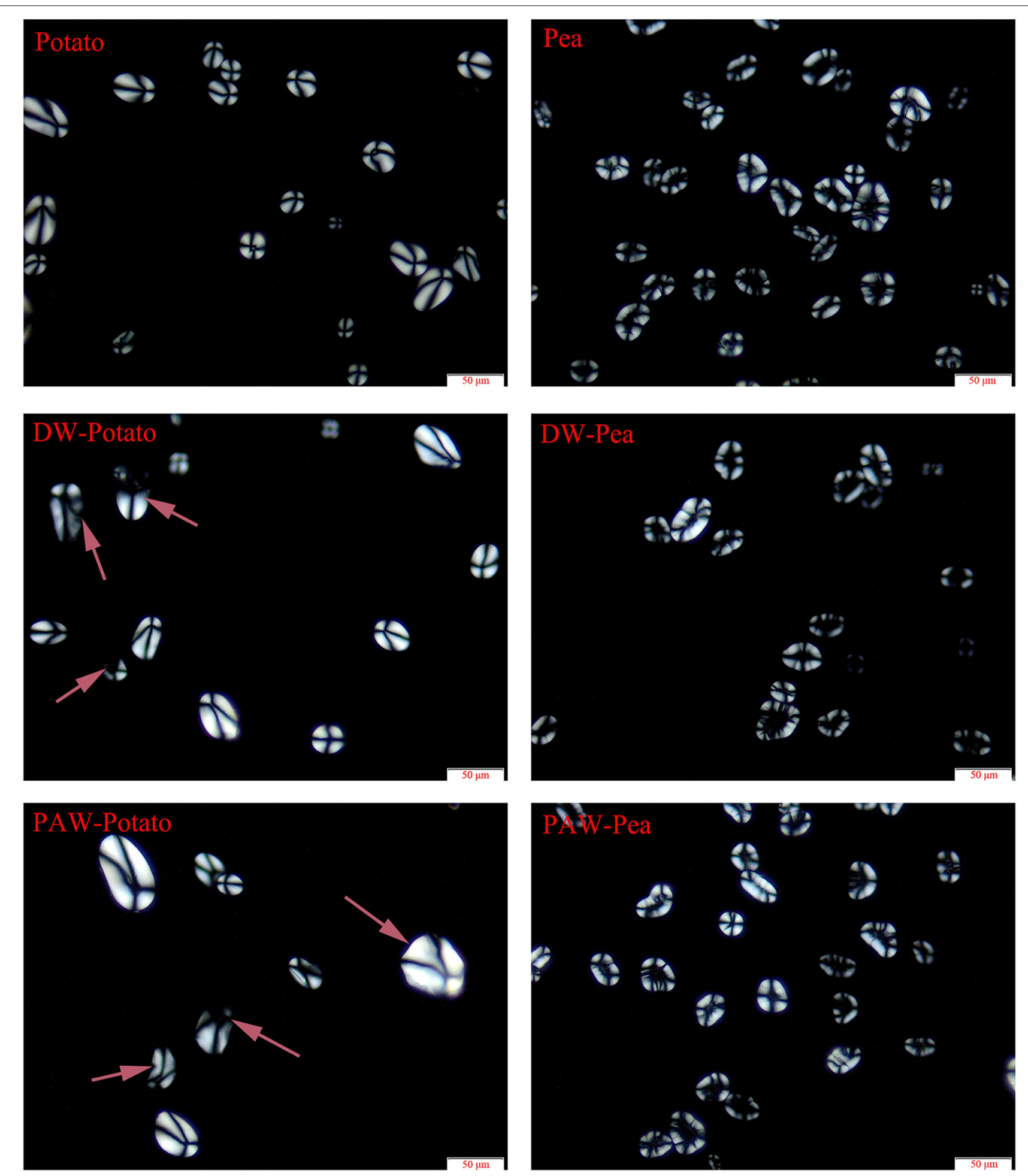

FIGURE 2 | Polarized light microscopy (PLM) images of native and modified starches.

SEM and PLM of DW-Potato and PAW-Potato. In addition, the RC of PAW-Potato was lower than that of DW-Potato, which may be attributed to the acidic content of PAW. ANN could increase the sensitivity of potato starch to acid hydrolysis, resulting in its crystal structure being more easily hydrolyzed (15). The characteristic diffraction peaks of pea starch were 

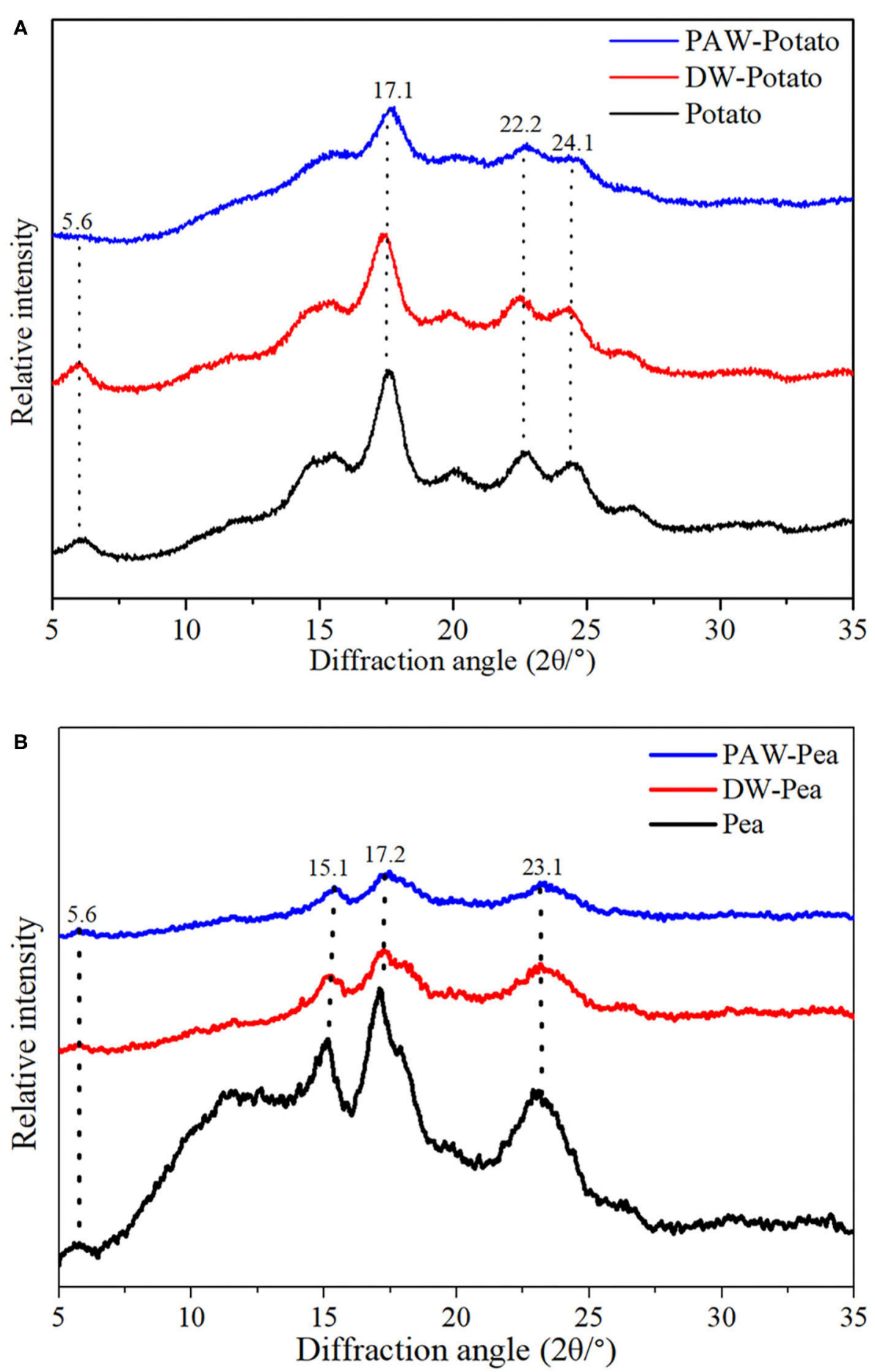

FIGURE 3 | X-ray diffraction (XRD) patterns of native and modified starches. (A) Native, distilled water-annealing (DW-ANN) treated, and plasma-activated water-annealing (PAW-ANN) treated potato starch. (B) Native, DW-ANN treated, and PAW-ANN treated pea starch.

mainly shown at $2 \theta=5.6,15.1,17.2$, and $23.1^{\circ}$, which belonged to the diffraction of C-type starch (16). It can be concluded from Table 2 that the crystallinity of ANN-modified pea starch (DW-Pea and PAW-Pea) was higher than that of native pea starch. This might be because ANN made the initially weak or imperfect crystallites of pea starch gradually disappeared, while the remaining crystallites became more perfect due to melting and recrystallization (17). In addition, the RC of PAW-Pea was 
TABLE 2 | Long-range, short-range ordered structure, and thermal properties of native and modified starches.

\begin{tabular}{|c|c|c|c|c|c|c|}
\hline Samples & RC (\%) & $\mathbf{R}_{1047 / 1022}$ & $\mathrm{~T}_{\circ}\left({ }^{\circ} \mathrm{C}\right)$ & $\mathbf{T}_{\mathrm{p}}\left({ }^{\circ} \mathrm{C}\right)$ & $\mathbf{T}_{\mathrm{c}}\left({ }^{\circ} \mathbf{C}\right)$ & $\Delta \mathbf{H}(\mathbf{J} / \mathrm{g})$ \\
\hline Potato & $25.16 \pm 0.35^{a}$ & $0.905 \pm 0.003^{a}$ & $57.34 \pm 0.24^{c}$ & $61.59 \pm 0.23^{b}$ & $72.10 \pm 0.67^{b}$ & $12.27 \pm 0.43^{a}$ \\
\hline DW-Potato & $22.13 \pm 0.21^{b}$ & $0.862 \pm 0.025^{a}$ & $62.32 \pm 0.18^{a}$ & $66.32 \pm 0.17^{a}$ & $74.33 \pm 0.72^{a}$ & $9.39 \pm 0.18^{b}$ \\
\hline PAW-Potato & $15.20 \pm 0.41^{c}$ & $0.783 \pm 0.057^{b}$ & $61.86 \pm 0.16^{b}$ & $66.04 \pm 0.11^{a}$ & $73.32 \pm 0.38^{a}$ & $7.31 \pm 0.20^{\circ}$ \\
\hline Pea & $25.40 \pm 0.26^{c}$ & $0.877 \pm 0.018^{b}$ & $57.92 \pm 0.04^{b}$ & $65.07 \pm 0.06^{b}$ & $75.58 \pm 0.06^{b}$ & $6.69 \pm 0.20^{c}$ \\
\hline DW-Pea & $30.53 \pm 0.31^{b}$ & $0.905 \pm 0.011^{\mathrm{ab}}$ & $66.97 \pm 0.01^{a}$ & $69.74 \pm 0.02^{a}$ & $76.25 \pm 0.12^{b}$ & $8.50 \pm 0.23^{b}$ \\
\hline PAW-Pea & $34.93 \pm 0.25^{a}$ & $0.934 \pm 0.001^{a}$ & $66.92 \pm 0.05^{a}$ & $69.76 \pm 0.03^{a}$ & $78.42 \pm 0.44^{a}$ & $9.66 \pm 0.11^{a}$ \\
\hline
\end{tabular}

Values are means $\pm S D$; means with the same letters in a column for the same starch do not differ significantly $(p>0.05)$.

higher than that of DW-Pea, indicating that PAW can improve the RC of pea starch during ANN. This may be due to more hydrolysis of the amorphous area by the acidic components of PAW, resulting in a better orientation of the hydrolyzed starch crystallites (18).

\section{Short-Range Ordered Structure}

The spectra of all starches showed similar trends, indicating that no new functional groups were formed (Figure 4). Studies have shown that the IR bands at 1,047 and $1,022 \mathrm{~cm}^{-1}$ were related to the ordered structure and amorphous structure of starch, respectively (19). The absorbance ratio of them $\left(\mathrm{R}_{1047 / 1022}\right)$ can indicate the relative content of the short-range ordered structure of starch. $\mathrm{R}_{1047 / 1022}$ of native and modified starches followed the order: Potato > DW-Potato > PAW-Potato; Pea $<$ DW-Pea $<$ PAW-Pea (Table 2). For potato starch, $\mathrm{R}_{1047 / 1022}$ decreased successively because ANN caused starch granules to form granular pores, ruptures, and cracks, resulting in damage to the internal ordered structure. The presence of PAW further aggravated the destruction process. For pea starch, $\mathrm{R}_{1047 / 1022}$ increased sequentially, which might be due to the high moisture content and moderate heat energy existing in the ANN process that could produce more effective double helix stacking (6). Moreover, the acidic components of PAW could affect amorphous regions of starch and generate more shortchain amylose to form a new double helices structure. The result of $\mathrm{R}_{1047 / 1022}$ was in agreement with the result of XRD.

\section{Thermal Properties}

The differential scanning calorimetry (DSC) curves of native and modified starches are shown in Figure 5. Table 2 presented the gelatinization transition temperatures (To, Tp, and Tc) and gelatinization enthalpy $(\Delta \mathrm{H})$. ANN resulted in a significant increase in the gelatinization temperatures of starch because ANN enhanced the interaction between amylose and amylose or amylopectin (20), inhibiting granule swelling and delaying gelatinization. However, the gelatinization temperatures of starches treated by DW-ANN and PAW-ANN were not significantly different. For potato starch, DW-ANN reduced the $\triangle \mathrm{H}$, and PAW-ANN can reduce the $\Delta \mathrm{H}$ more, from 12.27 to $7.31 \mathrm{~J} / \mathrm{g}$. The decrease of the $\Delta \mathrm{H}$ after $\mathrm{ANN}$ indicated the dissociation of unstable double helices in some starch granules (21), and the addition of PAW made this change more dramatic. For pea starch, DW-ANN increased the $\Delta \mathrm{H}$, and
PAW-ANN can increase the $\Delta \mathrm{H}$ more, from 6.69 to $9.66 \mathrm{~J} / \mathrm{g}$. The increase of the $\Delta \mathrm{H}$ after $\mathrm{ANN}$ indicated more increase of effective double helix stacking in pea starch granules (22). After PAW-ANN, the increase of $\Delta \mathrm{H}$ was due to the formation of new double helices, which was caused by the hydrolysis of amorphous regions (23). The $\Delta \mathrm{H}$ result was in line with XRD and FTIR results.

\section{Pasting Properties}

The pasting characteristics curves of native and modified starches are presented in Figure 6. The viscosity change of starch granules under heating and shearing was attributed to the tightly deformed granule arrangement, the friction between the expanded granules, and the content of leached amylose and amylopectin (24). After ANN, the peak viscosity of both potato and pea starches decreased, and the peak viscosity of modified potato starch decreased more. This might be associated with a significant increase in the interaction between amylose and amylose or amylopectin, inhibiting granule swelling, which was concluded from the increase of the gelatinization temperatures of starch (25). Moreover, compared with DW-ANN, PAWANN resulted in a lower peak viscosity. The decrease of viscosity could be because the starch chains were largely affected by acid hydrolysis, which generated fragmentation of starch chains (26).

\section{Dynamic Rheological Properties}

The dynamic rheological properties of native and modified starch pastes are displayed in Figure 7. $G^{\prime}$ and $G^{\prime \prime}$ are used to represent the elasticity and viscosity of starch gels, respectively (27). Tan $\delta$ was the ratio of $G^{\prime \prime}$ and $G^{\prime}$, which represents the viscoelastic properties of the starch gels (28). It can be illustrated from the Figures 7A-D that the $G^{\prime}$ and $G^{\prime \prime}$ of all starch pastes increased with increasing sweeping frequency and $\mathrm{G}^{\prime}$ was larger than $\mathrm{G}^{\prime \prime}(\tan \delta<1)$, revealing that starch pastes were a typical weak gel structure and more elastic (29). After ANN, all modified starches showed higher $G^{\prime}$ and $G^{\prime \prime}$, which explained that the gel strength of starch was enhanced. This may be because, during ANN, the rearrangement of amylose units formed on the surface of starch granules through larger pores and cracks increased the gel strength of starch (30). This can be demonstrated from the $\tan \delta$ (Figures 7E,F). The starch pastes after ANN had a smaller $\tan \delta$, indicating that the solid properties of the modified starch pastes were enhanced with 

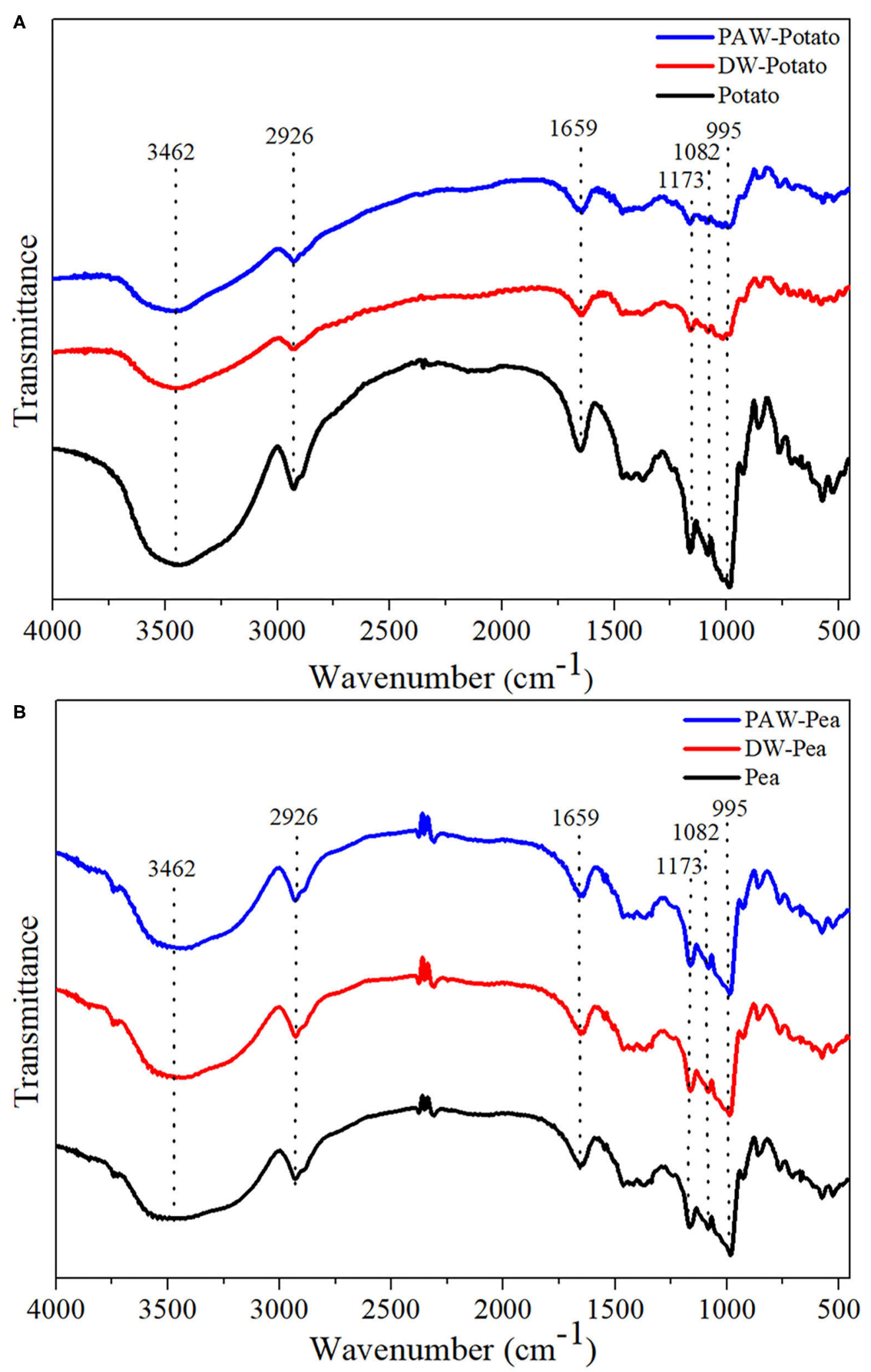

FIGURE 4 | Fourier transform infrared (FTIR) spectra of native and modified starches. (A) Native, DW-ANN treated, and PAW-ANN treated potato starch. (B) Native, DW-ANN treated, and PAW-ANN treated pea starch. 

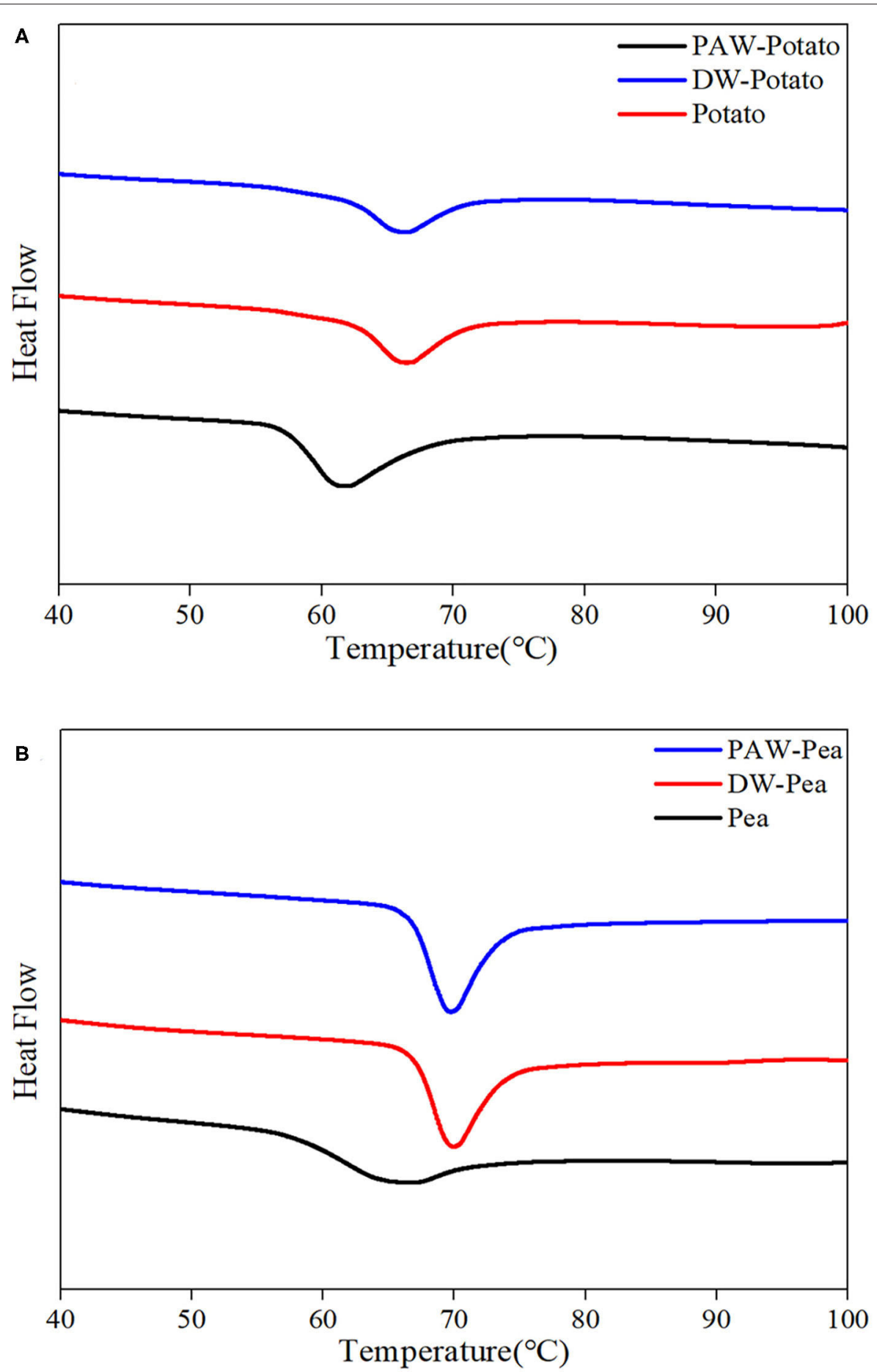

FIGURE 5 | Thermal properties of native and modified starches. (A) Native, DW-ANN treated, and PAW-ANN treated potato starch. (B) Native, DW-ANN treated, and PAW-ANN treated pea starch.

the higher gel strength. In addition, pea starch had lower $\tan \delta$ than potato starch. Notably, compared with DW-ANN, PAWANN resulted in larger $G^{\prime}$ and $G^{\prime \prime}$, and smaller $\tan \delta$, which indicated that the starch treated by PAW-ANN had higher gel strength than that treated by DW-ANN. Therefore, PAW-ANN modified starches had the highest gel strength and will be a potential gelling agent for soft candies, ice cream, and meat foods production. 

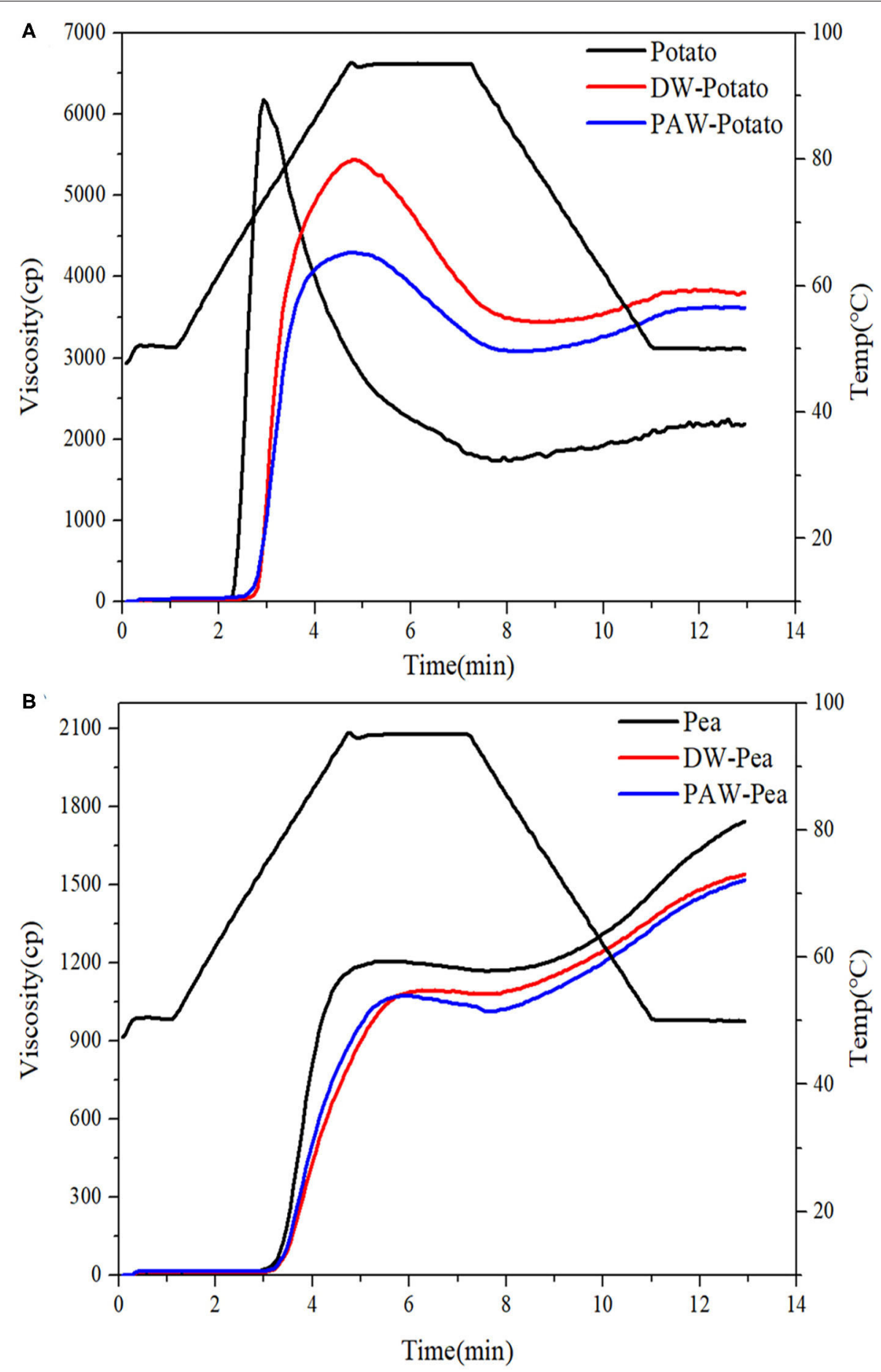

FIGURE 6 | Pasting curves of native and modified starches. (A) Native, DW-ANN treated, and PAW-ANN treated potato starch. (B) Native, DW-ANN treated, and PAW-ANN treated pea starch.

\section{CONCLUSION}

In summary, PAW-ANN as a completely novel starch modification method, had an obvious effect on the structure, thermal, pasting, and rheological properties of potato and pea starches. The impact of PAW-ANN on the granular morphology of two starches was not significantly different from the conventional DW-ANN. Compared with DW-ANN, PAW-ANN increased long and short-range ordered structure, and gelatinization enthalpy of pea starch while decreasing these 


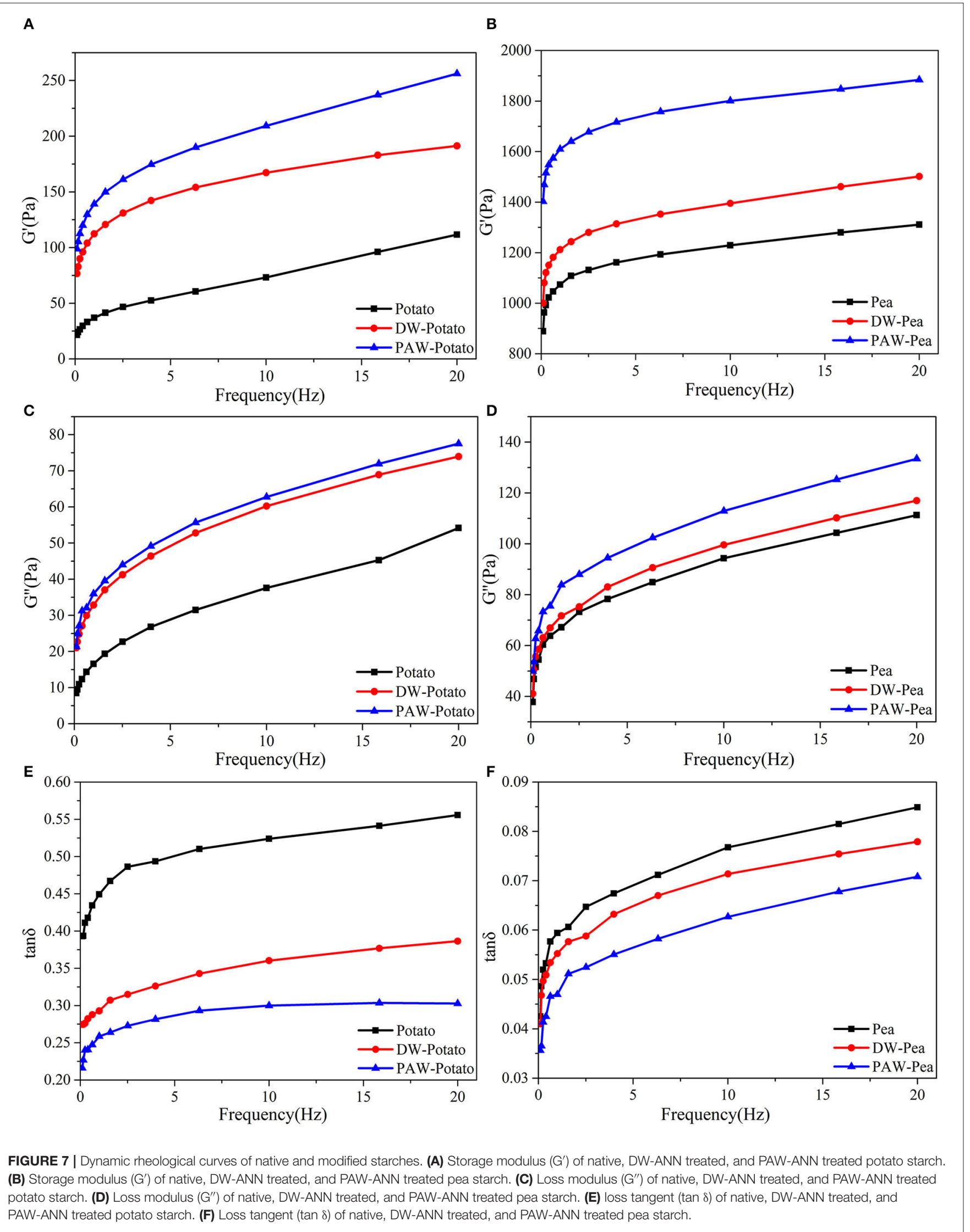


indicators of potato starch. In addition, PAW-ANN resulted in the lowest peak viscosity and the highest gel strength of the paste for two starches. Although, the exact mechanism was not clear, an acidic component in PAW might be an important factor for starch modification according to previous studies and above experimental results. This research showed that PAW-ANN provided innovative insights and novel technologies for the production of new modified starches applied to starch-based hydrogels and food additives.

\section{DATA AVAILABILITY STATEMENT}

The original contributions presented in the study are included in the article/supplementary material, further inquiries can be directed to the corresponding author/s.

\section{REFERENCES}

1. Fujita A. Starch. In: Encyclopedia of Applied Plant Sciences, 2nd Edn. Amsterdam: Academic Press; Elsevier (2017). p. 106-11.

2. Kaur M, Singh S. Influence of heat-moisture treatment (HMT) on physicochemical and functional properties of starches from different Indian oat (Avena sativa L.) cultivars. Int J Biol Macromol. (2019) 122:312-9. doi: 10.1016/j.ijbiomac.2018.10.197

3. Yadav BS, Guleria P, Yadav RB. Hydrothermal modification of indian water chestnut starch: influence of heat-moisture treatment and annealing on the physicochemical, gelatinization and pasting characteristics. LWT Food Sci Technol. (2013) 53:211-7. doi: 10.1016/j.lwt.2013.02.007

4. Zhang F, Zhang Y, Thakur K, Zhang J, Wei Z. Structural and physicochemical characteristics of lycoris starch treated with different physical methods. Food Chem. (2018) 275:8-14. doi: 10.1016/j.foodchem.2018. 09.079

5. Guo B, Wang Y, Pang M, Wu J, Hu X, Huang Z, et al. Annealing treatment of amylose and amylopectin extracted from rice starch. Int J Biol Macromol. (2020) 164:3496-500. doi: 10.1016/j.ijbiomac.2020. 08.245

6. Chung H, Liu Q, Hoover R. Impact of annealing and heat-moisture treatment on rapidly digestible, slowly digestible and resistant starch levels in native and gelatinized corn, pea and lentil starches. Carbohydr Polym. (2009) 75:436-47. doi: 10.1016/j.carbpol.2008.08.006

7. Thirumdas R, Kothakota A, Annapure U, Siliveru, K, Blundell R, et al. Plasma activated water (PAW): chemistry, physico-chemical properties, applications in food and agriculture. Trends Food Sci Technol. (2018) 77:2131. doi: 10.1016/j.tifs.2018.05.007

8. Yan Y, Feng L, Shi M, Cui C, Liu Y. Effect of plasma-activated water on the structure and in vitro digestibility of waxy and normal maize starches during heat-moisture treatment. Food Chem. (2020) 306:125589. doi: 10.1016/j.foodchem.2019.125589

9. Wang S, Wang J, Wang S, Wang S. Annealing improves paste viscosity and stability of starch. Food Hydrocoll. (2017) 62:203-11. doi: 10.1016/j.foodhyd.2016.08.006

10. Adhikari B, Adhikari M, Ghimire B, Park G, Choi EH. Cold atmospheric plasma-activated water irrigation induces defense hormone and gene expression in tomato seedlings. Sci Rep. (2019) 9:16080. doi: 10.1038/s41598-019-52646-z

11. Piecyk M, Druzynska B, Oltarzewska A, Wolosiak R, Worobiej E, Ostrowska-Ligeza E. Effect of hydrothermal modifications on properties and digestibility of grass pea starch. Int J Biol Macromol. (2018) 118:2113-20. doi: 10.1016/j.ijbiomac.2018.07.063

12. Zhang B, Li X, Liu J, Xie F, Chen L. Supramolecular structure of Aand B-type granules of wheat starch. Food Hydrocoll. (2013) 31:68-73. doi: 10.1016/j.foodhyd.2012.10.006

\section{AUTHOR CONTRIBUTIONS}

YY contributed to the conception, design, and funding of the study. BP, XJ, and YH organized the database. BP wrote the first draft of the manuscript. BN and MS contributed to writingreview and editing. All authors contributed to the article and approved the submitted version.

\section{FUNDING}

We are grateful to the National Natural Science Foundation of China (32101945), the Program for Science and Technology Innovation Talents in Universities of Henan Province (20HASTIT037), and the Henan Youth Talent Support Project (2020HYTP046).

13. Varatharajan V, Hoover R, Li J, Vasanthan T, Nantanga KKM, Seetharaman K, et al. Impact of structural changes due to heat-moisture treatment at different temperatures on the susceptibility of normal and waxy potato starches towards hydrolysis by porcine pancreatic alpha amylase. Food Res Int. (2011) 44:2594606. doi: 10.1016/j.foodres.2011.04.050

14. Witt T, Doutch J, Gilbert EP, Gilbert RG. Relations between molecular, crystalline, and lamellar structures of amylopectin. Biomacromolecules. (2012) 13:4273-82. doi: 10.1021/bm301586x

15. Nakazawa Y, Wang Y. Acid hydrolysis of native and annealed starches and branch-structure of their naegeli dextrins. Carbohydr Res. (2003) 338:2871-82. doi: 10.1016/j.carres.2003.09.005

16. Shi M, Zhang Z, Yu S, Wang K, Gilbert RG, Gao Q. Pea starch (Pisum sativum L.) with slow digestion property produced using beta-amylase and transglucosidase. Food Chem. (2014) 164:317-23. doi: 10.1016/j.foodchem.2014.05.045

17. Lorenz K, Collins F, Kulp K. Steeping of starch at various temperatures-effects on functional properties. Starch. (1980) 32:181-6. doi: 10.1002/star.19800320602

18. Zhang H, Hou H, Liu P, Wang W, Dong H. Effects of acid hydrolysis on the physicochemical properties of pea starch and its film forming capacity. Food Hydrocoll. (2019) 87:173-9. doi: 10.1016/j.foodhyd.2018.08.009

19. Capron I, Robert P, Colonna P, Brogly M, Planchot V. Starch in rubbery and glassy states by FTIR spectroscopy. Carbohydr Polym. (2007) 68:249-59. doi: 10.1016/j.carbpol.2006.12.015

20. Zhang B, Wu C, Li H, Hu X, Jin Z, Tian Y, et al. Long-term annealing of C-type kudzu starch: effect on crystalline type and other physicochemical properties. Starch Stärke. (2015) 67:577-84. doi: 10.1002/star.201500003

21. Bahrani SA, Loisel C, Rezzoug SA, Cohendoz S, Buleon A, Maache-Rezzoug Z. Physicochemical and crystalline properties of standard maize starch hydrothermally treated by direct steaming. Carbohydr Polym. (2017) 157:38090. doi: 10.1016/j.carbpol.2016.10.009

22. Chung KM, Moon TW, Chun JK. Influence of annealing on gel properties of mung bean starch. Cereal Chem. (2000) 77:567-71. doi: 10.1094/CCHEM.2000.77.5.567

23. Wang L, Wang Y. Structures and physicochemical properties of acid thinned corn, potato and rice starches. Starch Stärke. (2001) 53:570-6. doi: 10.1002/1521-379X(200111)53:11<570::AID-STAR570>3.0.CO;2-S

24. Sasaki T, Yasui I, Matsuki J, Satake T. Comparison of physical properties of wheat starch gels with different amylose content. Cereal Chem. (2002) 79:861-6. doi: 10.1094/CCHEM.2002.79.6.861

25. Lan H, Hoover R, Jayakody L, Liu Q, Donner E, Baga M, et al. Impact of annealing on the molecular structure and physicochemical properties of normal, waxy and high amylose bread wheat starches. Food Chem. (2008) 111:663-75. doi: 10.1016/j.foodchem.2008.04.055

26. Zambelli RA, Galvao A, de Mendonca LG, Leao MVD, Carneiro SV, Lima ACS, et al. Effect of different levels of acetic, citric and lactic acid in the cassava 
starch modification on physical, rheological, thermal and microstructural properties. Food Sci Technol Res. (2018) 24:747-54. doi: 10.3136/fstr.24.747

27. Sudheesh C, Sunooj KV, Sinha SK, George J, Kumar S, Murugesan P, et al. Impact of energetic neutral nitrogen atoms created by glow discharge air plasma on the physico-chemical and rheological properties of kithul starch. Food Chem. (2019) 294:194-202. doi: 10.1016/j.foodchem.2019.05.067

28. Chen L, Tian Y, Bai Y, Wang J, Jiao A, Jin Z. Effect of frying on the pasting and rheological properties of normal maize starch. Food Hydrocoll. (2018) 77:85-95. doi: 10.1016/j.foodhyd.2017.09.024

29. Meriem-Benziane M, Abdul-Wahab SA, Benaicha M, Belhadri M. Investigating the rheological properties of light crude oil and the characteristics of its emulsions in order to improve pipeline flow. Fuel. (2012) 95:97-107. doi: 10.1016/j.fuel.2011.10.007

30. Sudheesh C, Sunooj KV, Anjali KU, Aaliya B, Navaf M, Kumar S, et al. Effect of lysine incorporation, annealing and heat moisture treatment alone and in combination on the physico-chemical, retrogradation, rheological properties and in vitro digestibility of kithul (Caryota urens L.) starch. Int J Food Sci Technol. (2020) 55:2391-8. doi: 10.1111/ijfs.14488
Conflict of Interest: The authors declare that the research was conducted in the absence of any commercial or financial relationships that could be construed as a potential conflict of interest.

Publisher's Note: All claims expressed in this article are solely those of the authors and do not necessarily represent those of their affiliated organizations, or those of the publisher, the editors and the reviewers. Any product that may be evaluated in this article, or claim that may be made by its manufacturer, is not guaranteed or endorsed by the publisher.

Copyright (c) 2022 Yan, Peng, Niu, Ji, He and Shi. This is an open-access article distributed under the terms of the Creative Commons Attribution License (CC BY). The use, distribution or reproduction in other forums is permitted, provided the original author(s) and the copyright owner(s) are credited and that the original publication in this journal is cited, in accordance with accepted academic practice. No use, distribution or reproduction is permitted which does not comply with these terms. 